\title{
Study on Prevalence of Ruminant Fasciolosis and its Associated Risk Factors in Kombolcha, North East Ethiopia
}

Shimels Tikuye*

EIAR, National Agricultural Biotechnology Research Center, Holleta, Ethiopia

\begin{abstract}
A cross sectional study was conducted to determine prevalence and risk factors associated with ruminant fasciolosis in Kombolcha, Amhara regional state from October 2010 to March 2011. For the purpose of the study fecal samples were taken from a total of 420 ruminants (168 cattle, 149 sheep and 103 goats) and subjected to coprological examination, specifically sedimentation technique. Based on the coproscopic examination the prevalence of fasciolosis was found to be $9.52 \%(n=16)$ in cattle, $37.58 \%(n=56)$ in sheep and $6.8 \%(n=7)$ in goats. Among the ruminants the prevalence of fasciolosis showed statistically significant variations $\left(X^{2}=53.6095, P=0.000\right)$, being very high in sheep and low in goats and poor body condition $45(60 \%)$. This study revealed the presence of statistical significant differences $\left(X^{2}=103.08, P=0.000\right)$ between the three body conditions, the prevalence recorded in poor condition animals was very high. On the contrary there was no significance difference $(P>0.05)$ in sex and age groups. In conclusion fasciolosis was found to be important ruminant disease in the study area, thus to control the disease and reduce the economic loss in this area, appropriate control strategies should be given.
\end{abstract}

Keywords: Coprology; Fasciolosis; Kombolcha; Prevalence; Ruminant; Sedimentation

Abbreviations: \%: Percent; ${ }^{\circ} \mathrm{C}$ : Degree Celsius, F. gigantica: Fasciola gigantica; F. hepatica: Fasciola hepatica; L. natalansis: Lymnaea natalansis; L. truncatula: Lymnaea truncatula; masl: meters above sea level; mm: millimetre; SPSS: Statistical Package for Social Science; USD: United States Dollar; EIAR: Ethiopian Institute Agriculture Research; $\mathrm{Km}$ : Killo meter; $\chi^{2}$ : Pearson chi square.

\section{Introduction}

Fasciolosis is among the important parasitic worm infection which limits productivity of animals due to mortality, reduced growth rate, reduction in weight gain and unthriffines, reduction in working power, condemnation of large number of infected liver, increased susceptibility to secondary infection and expense due to control measure. The parasite is caused by the common liver fluke Fasciola hepatica and F. gigantica. The disease is a plant-borne trematode zoonosis [1] and is categorized under a neglected tropical disease [2].

The genus Lymnea in general, species of $L$. truncatula and $L$. natalensis are the most common intermediate hosts for F. hepatica and $F$. gigantic respectively. These species of snail was reported to have a worldwide distribution [3]. F. gigantica is found in most continents, primarily in tropical regions [4].

The parasite is the most prevalent helminthes infection of ruminants found in most parts of the world including Ethiopia. F. hepatica is found in areas with altitude of 1200 to 2560 masl while, F. gigantica is found at altitudes bellow 1800 masl but both species co-exist in areas where altitude ranging between 1200 to 1800 masl [5].

According to Yilma J, Malones JB the economic losses of fasciolosis are mostly caused by mortality, morbidity, reduced growth rate, condemnation of liver, increased susceptibility to secondary infection and the expense of control measures [5]. According to Fufa and Rokni the average loss of Fasciola was 6300 USD and 4000 USD per annum in Jimma and wolayta soddo municipal abattoir respectively [6,7].

Coprological examination from faces by using standard sedimentation technique is used for the diagnosis of fasciolosis for detection of Fasciola eggs [8]. In the study area, ruminants are important asset to farmers but the data regarding to Ruminant fascioliosis are not well documented. Therefore, the objectives of this study were to determine the prevalence and to asses with the risk factors of ruminant fasciolosis in Kombolcha.

\section{Materials and Methods}

\section{Study area}

Kombolcha is a town in North- Eastern Ethiopia located in the south Wollo zone of the Amhara regional state, located $375 \mathrm{~km}$ North East of Addis Ababa, between $11^{\circ} 084^{\prime} 49^{\prime \prime}$ latitude and $0.39^{\circ} 737^{\prime} 46^{\prime \prime}$ longitude of with an elevation between 1500-1840 meter above sea level. Kombolcha experiences bimodal rainfall which is the short rainy season occurs usually from March to May and the long rainy season extends from June to September. The minimum and maximum mean annual rainfall ranges from 750 to $900 \mathrm{~mm}$, the annual temperature ranges from $11.8^{\circ} \mathrm{C}$ to $26^{\circ} \mathrm{C}$ and the relative humidity varies from $23.9 \%$ to $79 \%$.

\section{Study animals}

A total of 420 indigenous breeds of ruminants (cattle, sheep and goat) managed extensively were randomly selected and subjected to qualitative coproscopic examination by standard sedimentation technique to determine the prevalence rate of Fasciola in the study area. The selected animals were from different species, age, sex and body condition groups.

${ }^{*}$ Corresponding author: Shimels Tikuye, EIAR, National Agricultural Biotechnology Research Center, Holleta, PO Box: 249, Ethiopia, Tel: +251913796389; Fax: 0112610086; E-mail: shimelstk@gmail.com

Received July 02, 2017; Accepted July 18, 2017; Published July 19, 2017

Citation: Tikuye S (2017) Study on Prevalence of Ruminant Fasciolosis and its Associated Risk Factors in Kombolcha, North East Ethiopia. J Vet Sci Technol 8: 461. doi: 10.4172/2157-7579.1000461

Copyright: () 2017 Tikuye S. This is an open-access article distributed under the terms of the Creative Commons Attribution License, which permits unrestricted use, distribution, and reproduction in any medium, provided the original author and source are credited. 


\section{Study methodology}

Coproscopy was used to determine positivity of the animals for fasciola. Fecal samples for parasitological examination were collected directly from the rectum of each species, using disposable plastic gloves and placed in clean screw capped universal bottle and each sample was clearly labeled with animal identification, species, sex, age and body condition score. Fecal samples were preserved with $10 \%$ formalin solution to avoid the eggs developing and hatching. In the laboratory, coproscopic examinations were performed to detect the presence of Fasciola eggs using the standard sedimentation techniques. A drop of methylene blue solution was added to the sediment to differentiate it from eggs of paramphistomum. Eggs of Fasciola species show yellowish color while eggs of paramphistomum species stain by methylene blue [9].

\section{Sample size}

For estimation of Fasciola prevalence, the sample size was determined by assuming the expected prevalence to be $50 \%$, the statistical Confidence Interval level was $95 \%$ while the desired precision was $5 \%$ and a sample size of 384 ruminants (cattle, sheep and goat) was determined based on the formula given by Thrusfield [10]. However, a total of 420 ruminants were taken to increase the precision of the study.

$$
n=\frac{Z^{2} P_{e x p}\left(1-P_{e x p}\right)}{d^{2}}
$$

where, $\mathrm{n}=$ sample size,

$\mathrm{P}_{\exp }=$ expected prevalence,

$\mathrm{d}^{2}=$ desired precision,

$\mathrm{Z}=$ constant from normal distribution table at a given confidence level.

\section{Data analysis}

All raw data generated from the study were coded and entered in MS Excel database system. Using SPSS version 16 computer program, data were analyzed by using Chi-square $\left(\chi^{2}\right)$ test to determine the variation in infection, prevalence between species, sex, age and body condition score. Statistical significance was set at $\mathrm{P}<0.05$ to determine whether there are significant differences between the parameters measured between the groups.

\section{Results}

Coproscopic examination was conducted from October 2010 to March 2011 showed that from a total of 420 indigenous ruminants managed extensively examined for the presence of Fasciola by using sedimentation technique, 79 ruminants revealed Fasciola egg in their faces with an over all prevalence of $18.81 \%$.

The prevalence rate was higher in ovine $(37.58 \%)$ and lower in bovine $(9.52 \%)$ and caprine $(6.80 \%)$ species respectively. Infection rate was statistically significant $(\mathrm{P}<0.05)$ (Table 1$)$.

Prevalence of fasciolosis in male and female animals was $22.91 \%$ and $15.77 \%$ respectively. However, no significant difference $(\mathrm{P}>0.05)$ was observed between sexes (Table 1).

The highest prevalence was recorded in ruminants aged $1<\mathrm{x}<3$ years $(20.41 \%)$ and $>3$ years $(20.00 \%)$. Meanwhile, low prevalence was observed in less than 1 year with value $(15.45 \%)$. But this difference was not statistically significant $(\mathrm{p}>0.05)$ (Table 1$)$. Where $\mathrm{X}$ - represent age in terms of years
The prevalence of ruminant fasciolosis in animals with a poor body condition (60\%) was higher than animals with medium (12.5\%) and good body condition (7.10\%) respectively. Significant difference $(\mathrm{P}<0.05)$ in prevalence was observed among body condition of the study animals (Table 1).

\section{Discussion}

Fasciolosis in ruminants was found with prevalence rates of $9.52 \%$ $(\mathrm{n}=16)$ bovine, $37.58 \%(\mathrm{n}=56)$ ovine and $6.79 \%(\mathrm{n}=7)$ of caprine and with over all prevalence rate of $18.81 \%$ of ruminants from coproscopic result. It showed a statistically significant difference $(\mathrm{p}<0.05)$ between bovine, ovine and caprine. This difference may be due to species sensitivity to Fasciola, thus animals, like cattle's have a moderate to high degree of resistance to primary infection. But sheep and goats do not develop a protective immunity to re-infection while cattle's develop immunity to defend infections and develop protection against re-infection with Fasciola [11]. Caprines have lowered prevalence of fasciolosis when compared with bovine and ovine. This may be due to the fact that goats are browsers. These differences could be due to difference in management system, grazing habit and resistance to parasitic infection. Similar result support the present finding is reported by Henok [12] in and around Hirna town.

The prevalence rate of bovine fasciolosis was $9.52 \%(n=16)$ in the study area. This was lowered when compared with $41.41 \%$ in and around Woreta [13], 34.04\% in Turkey but the present study was higher than $4.9 \%$ in Soddo $[7,14]$. This variation may be due to the agro-ecological and climatic differences between the localities, although differences in the management systems and sample size.

The prevalence of ovine fasciolosis was found to be $37.5 \%(n=56)$ in the study area. This finding was lower when compared with previous reports in different parts of the country by Molalegne [15] 49\% in and around Dawa-Cheffe, [16] 56.3\% in Upper Awash River Basin, but higher than that of Ahmed [17] 13.2\% in Middle Awash River Basin. These variations may be due to differences in temperature, moisture, humidity and soil for multiplication of intermediate host.

The prevalence of caprine fasciolosis was found to be $6.8 \%$. This result is lower when compared with Adediran [18] 9.1\% in Ibadan, Nigeria. This may be due to difference in climatic conditions, geographical regions and sample size of the study.

The prevalence of Fasciola in male and female ruminants was recorded as $22.91 \%$ and $15.77 \%$ respectively. There was non-significant difference $(\mathrm{P}>0.05)$ between the two sexes indicating that sex have no effect on disease prevalence. This may be probably due to that grazing habit of both sex groups in similar pasture land. Similar findings that strengthen the present result are reported by Mulualem and Ashenafi $[19,20]$. But, Balock indicated that high prevalence rate in the male than female [21]. This may be due to the management system with more time exposure of male to the field while females are kept in door system during pregnancy and lactation period.

The prevalence of ruminant fasciolosis among $>3$ years $(20 \%)$ and $1<\mathrm{x}<3$ years $(20.41 \%)$ was higher than that of $<1$ year $(15.45 \%)$, but this difference was not statistically significant. The higher infection rate in $1<\mathrm{X}<3$ years and $>3$ years animals could be due to long time exposure to disease entity and their grazing habit close to submerge areas [22].

Prevalence of ruminant fasciolosis was also carried out based on the basis of body condition. Poor body condition animals were significantly higher $(\mathrm{P}<0.05)$ than that of medium and good body condition animals 
Citation: Tikuye S (2017) Study on Prevalence of Ruminant Fasciolosis and its Associated Risk Factors in Kombolcha, North East Ethiopia. J Vet Sci Technol 8: 461. doi: 10.4172/2157-7579.1000461

Page 3 of 4

\begin{tabular}{|c|c|c|c|c|c|c|}
\hline Risk factors & No. examined & No. positive & Prevalence (\%) & $x^{2}$ & $p$-value & $\mathrm{Cl}$ \\
\hline \multicolumn{7}{|l|}{ Species } \\
\hline Bovine & 168 & 16 & 9.52 & 53.6095 & 0.000 & \multirow{18}{*}{$95 \%$} \\
\hline Ovine & 149 & 56 & 37.58 & & & \\
\hline Caprine & 103 & 7 & 6.80 & & & \\
\hline Total & 420 & 79 & 18.81 & & & \\
\hline \multicolumn{6}{|l|}{ Sex } & \\
\hline Male & 179 & 41 & 22.91 & 3.4262 & 0.064 & \\
\hline Female & 241 & 38 & 15.77 & & & \\
\hline Total & 420 & 79 & 18.81 & & & \\
\hline \multicolumn{6}{|c|}{ Age } & \\
\hline$<1$ year & 123 & 19 & 15.45 & 1.2958 & 0.523 & \\
\hline $1<x<3$ years & 147 & 30 & 20.41 & & & \\
\hline$>3$ years & 150 & 30 & 20.00 & & & \\
\hline Total & 420 & 79 & 18.81 & & & \\
\hline \multicolumn{6}{|l|}{ Body condition } & \\
\hline Poor & 75 & 45 & 60 & 103.0842 & 0.000 & \\
\hline Medium & 176 & 22 & 12.50 & & & \\
\hline Good & 169 & 12 & 7.10 & & & \\
\hline Total & 420 & 79 & 18.81 & & & \\
\hline
\end{tabular}

Table 1: Prevalence of Ruminant fasciolosis and its association with various risk factors in Kombolcha.

respectively. This indicates that the importance of fasciolosis in causing loss of appetite and poor utilization of food, which results in a loss of body weight. This finding agrees with [17] in Middle Awash River Basine, [23] in Adigrat and [24] in Yilmana Densa district.

\section{Conclusion}

Fasciolosis is one of the major helminth infections for ruminant production in the study area. This prevalence found in the study area could be also due to the water lodgment from Borkena River which increased irrigated land masses and ponds at grazing areas of animals and the trend of livestock owners to graze their animals in these areas at the time of feed scarcity. The Observed differences in the prevalence of parasitic infections between species were probably due to differences in grazing habit and host susceptibility to infection. Therefore, Strategic anthelmentic treatment with appropriate fluckcidal drugs, a combination of control measures including drainage, fencing and mulluscicides and awareness creation should be implemented to control the helminthes infection.

\section{Acknowledgements}

I would like to express my heartly thanks to Dr. Mullugeta Tefera for his technical advice, over all guidance and valuable comments on my draft documents to appear in the present form. My special thanks go to my families with their advice, moral and financial support during the study period. Lastly but not least I would like to express my thanks to Kombolcha Regional Veterinary Diagnostic Laboratory for their logistic support.

\section{References}

1. Mas-Coma S, Bargues MD, Valero MA (2005) Fascioliasis and other plantborne trematode zoonoses. Int J Parasitol 35: 1255-1278.

2. Farrar J, Hotez P, Junghanss T, Kang G, Lalloo D, et al. (2013) Manson's Tropical Diseases. J Elsevier Health Sciences.

3. Urquhart GM, Duncan J, Armour L, Dunn J, Jennings AM (1996) Veterinary parasitology second edition, Black well science, UK.

4. Dalton JP, Spithil TW (1998) Progress in development of liver fluke vaccine. Trends Parasitol 14: 224-228.

5. Yilma J, Malones JB (1998) A geographical information system forces mode for strategic control of fasciolosis. In: Ethiopia Vet Parasitol 78: 103-127.

6. Taddele T, Worku T (2007) The prevalence and economic significance of bovine fasciolosis at Jimma abattoir, Ethiopia. Internet J Vet Med 3: 15.

7. Fufa A, Loma A, Bekele M, Alemayehu R (2009) Bovine fasciolosis: coprological abattoir survey and its economic impact due to liver condemnation at Soddo municipal abattoir, Southern Ethiopia. Trop Anim Health Prod 42: 289-292.

8. Rokni MB, Massoud J, Kia EB (2003) Comparison of Adult Somatic and cysteine proteinase antigens of Fasciola gigantica in Enzyme linked Immunosorbent Assay for diagnosis of bovine Fasciolosis. In: DIE seminar on biotechnology, proceeding November 9-13, Tehran, Iran.

9. Hanson J, Brian P (1994) The epidemiology, diagnosis and control of helminthes parasites of ruminants. A hand book, Rome: Food and Agricultural Organization of the United Nations. Pp: 72.

10. Thrusfield MV (2005) Veterinary Epidemiology. 3rd ed., Blackwell Science, Oxford, pp: 234-238.

11. Soulsby EJL (1982) Helminthes, Arthropods and protozoa of domesticated Animals, seventh edition, Balliere. Tindall and London, UK; pp. 40-52.

12. Henok M, Mekonnen A (2011) Study on the Prevalence and Risk Factors of Fasciolosis in Small Ruminants in and around Hirna Town, Ethiopia. Global Veterinaria 7: 497-500.

13. Binyam T, Hanna A, Sisay G (2012) Study on coprological prevalence of Bovine fasciolosis in and around Woreta, Northwestern Ethiopia. J Vet Med Anim Health 4: 89-92.

14. Avcioglu H, Guven E, Balkaya I, Kaynar O, Hayirli A (2014) Evaluation of Coprological and Serological Techniques For Diagnosis of Bovine Fasciolosis. Israel J Vet Med 69: 203-210.

15. Molalegne B, Nuradis I, Nahili A (2010) Study on the prevalence of Ovine fasciolosis in and around Dawa-Cheffa, Kemissie. African J Agric Res 5: 2981-2985.

16. Michael A, Beyene P, Yilma J, Don P, Yoseph S, et al. (2004) Infection prevalence of ovine fasciolosis in small irrigation schemes along the Upper Awash River Basin. Ethiopia Vet J 9: 19-26.

17. Ahmed EF, Markvichitr K, Jumwasorn S, Koonawoothtthin S, Achoothesa JS (2007) Prevalence of fasciola Species infections of sheep in the middle awash river basin, Ethiopia. Southeast Asian J Trop Med Publ health 38: 51-52.

18. Adediran OA, Adebiyi Al, Uwalaka EC (2014) Prevalence of Fasciola species in ruminants under extensive management system in lbadan southwestern Nigeria. Afr J Med Med Sci 43: 137-141.

19. Mulualem E (1998) Epidemiology of bovine, Fasciolosis in woredas of south Gonder administrative zone bordering Lake Tana. Ethiopian Vet J 2: 1-13.

20. Ashenafi K, Birhan T, Alemu A, Biniam T (2016) Prevalence of fasciolosis in small ruminants and associated risk factor in and around Kombolcha. J Adv Parastol 3: 61-65. 
Citation: Tikuye S (2017) Study on Prevalence of Ruminant Fasciolosis and its Associated Risk Factors in Kombolcha, North East Ethiopia. J Vet Sci Technol 8: 461. doi: 10.4172/2157-7579.1000461

Page 4 of 4

21. Balock FC, Arthur RJ (1985) A Survey of fasciolosis in beef cattle killed at abattoir in Southern Queen land. Australian Vet J 62: 320-326.

22. Tasawar ZU, Minir CS, Hayat M, Lashari H (2007) The prevalence of Fasciola hepatica in goats around Multan. Pak Vet J 27: 5-7.
23. Eyerusalem G, Yeshitila A, Mihreteab B (2012) Prevalence of Ovine Fasciolosis in Adigrat, North East Ethiopia. Global Veterinaria 9: 92-96.

24. Basaznew B, Abeje M, Mersha C (2012) Pervasiveness of Fasciolosis in Sheep in YilmanaDensa District, West Gojjam Zone, Amhara Region, Northwestern Ethiopia. Acta Parasitological Globalist 3: 34-37. 